\title{
Las huellas del Islam en la Meseta norte
}

\author{
Julio Valdeón Baruque *
}

El Islam y España son, de alguna manera, inseparables. Independientemente de que se acepte o no el punto de vista de Américo Castro de la simbiosis medieval de las tres castas puede afirmarse que la historia de España nos resultaría incomprensible en su conjunto si olvidáramos la aportación a la misma del mundo musulmán. Pero al mismo tiempo la Península lbérica constituye un capítulo imprescindible de cualquier historia universal de la civilización islámica. Hubo, durante siglos, un "Islam de España", y sus huellas, tanto materiales como espirituales, son aún perceptibles hoy en día.

Ahora bien, no todas las regiones de España vivieron con la misma intensidad la presencia de lo islámico en su suelo. Frente a ámbitos territoriales como Andalucía, Aragón o el antiguo reino de Valencia, en donde el pasado islamita le sale al paso al viajero a cada momento, en forma de topónimos, restos de antiguas mezquitas, paisajes urbanos, influencias artísticas claramente perceptibles, etc., otros, tal es el caso de la Meseta norte (tierras de Castilla la Vieja y del antiguo reino de León), parecen hallarse casi en los antípodas. En efecto, podemos hacernos la pregunta, ¿hasta qué punto participó la meseta del Duero en el florecimiento pretérito del Islam de España?, ¿cuál ha sido la herencia musulmana en la Meseta septentrional, o más exactamente en el territorio hoy configurado en la comunidad autónoma de Castilla y León?

\footnotetext{
* Universidad de Valladolid.
} 
Ciertamente las opiniones al respecto oscilan entre polos opuestos. Hay historiadores que niegan toda virtualidad a la presencia de lo arábigo en la cuenca del Duero, considerando, por el contrario, que esa región fue el crisol en el que se constituyó una peculiar vividura hispano-cristiana, cuyo rasgo más significativo fue su espíritu de cruzada permanente frente a los infieles. "Nunca fue conquistado por los moros el primitivo territorio de Castilla", afirmaba a principios de este siglo el padre benedictino Luciano Serrano. La frase, más allá de la veracidad o no de lo que indica, trataba de manifestar el orgullo de una supuesta pureza cristiana, libre de toda contaminación islamita. Otros investigadores, por el contrario, insisten en poner de relieve las huellas de la cultura arábiga en la Meseta norte. Quizá el caso más llamativo, a este respecto, lo constituye Oliver Asín, el cual ha defendido la hipótesis de que hasta el mismo nombre de Castilla es de origen islamita. Para este autor Castilla no deriva del latín castellum, sino del árabe Qastilya, término que designaba a una comarca del actual Túnez. El paralelismo que Oliver encontraba entre las instituciones de la Qastilya tunecina de los siglos vill y IX y las de la Castilla de los condes cristianos explicaría suficientemente la traslación lingüística del término arábigo a la Meseta del Duero.

¿Dónde situarse a la vista de opiniones tan dispares? En principio parece razonable admitir que la Meseta norte no ejerció un especial atractivo sobre los musulmanes que llegaron a la Península lbérica en los primeros años del siglo vill. La Meseta del Duero se encontraba al norte de esa línea (real, por cuanto se apoyaba en el Sistema Central, pero a la vez imaginada) que separaba "dos realidades ecológicas", como ha dicho T. F. Glick. Esa contraposición entre un mundo más tosco, básicamente agrario, al norte, y otro más desarrollado, con un fuerte componente urbano y artesanal, al sur, la recogen, entre otros autores islamitas, Al-Razi, en el siglo Xl, y Edrisi en el XII. Por lo demás, numerosos textos árabes de los siglos VIII y IX utilizan expresiones como el "yermo" o el "gran desierto" (aún admitiendo que hay que ser muy cautos a la hora de contextualizar esos términos) al referirse a la cuenca del Duero. «Te he abandonado para combatir al enemigo, he tenido que atravesar el desierto", se lee en un texto de Ibn 'Idari de mediados del siglo Ix en el que se habla de un cortesano que comunica a la favorita de su harén que ha partido en combate contra los cristianos de la zona del Cantábrico, para lo cual se ha visto precisado a cruzar la Meseta norte. En torno al año 925 el ejército califal de Abd al Rahman III, dice otra fuente árabe coetánea de aquellos acontecimientos, tardó cinco días «en cruzar el gran desierto», aludiendo en esta ocasión a la región soriana, que hubo que atravesar para llegar hasta Tudela. 
Ahora bien, si dejándonos llevar de esos datos sacáramos la conclusión de que el territorio de Castilla la Vieja y el antiguo reino de León se mantuvieron ajenos a la penetración de la civilización arábiga, cometeríamos un craso error. Precisamente en los siglos de formación de León y de Castilla, VIII al XI, la dependencia en que se encontraban los núcleos cristianos de la Península con respecto a Al-Andalus explica que hubiera una masiva adaptación en las tierras de los primeros de novedades culturales procedentes del ámbito musulmán. "Las sociedades y las culturas están más abiertas a la innovación en los períodos formativos», señala T. F. Glick. Es necesario, por supuesto, que existan agentes de esos préstamos, lo que sin duda sucedió, en el caso que nos ocupa, con los beréberes y los mozárabes.

En cualquier caso basta con efectuar un recorrido por la cuenca del Duero para encontrarse con huellas palpables del influjo arábigo. En unos casos son los topónimos: Almonacid o Alcazarén, Castroserracín o Mezquitillas, Mahamud o Mazote, por mencionar sólo unos cuantos ejemplos. En otros casos la influencia muslim está presente en iglesias o en castillos (pensemos, como muestras señeras, en Santa Clara de Tordesillas, en el primer supuesto, o el castillo de Coca, en el segundo).

\section{LOS BERÉBERES}

Efectuando un somero repaso de la presencia islámica en tierras de la Meseta norte, al hilo de la cronología, encontramos como primer eslabón de la cadena a los beréberes. Originarios del norte de Africa, los beréberes habían colaborado, junto a otros grupos musulmanes, en la conquista de la Península lbérica en los primeros años del siglo VIII. Al poco tiempo los encontramos asentados en la cuenca del Duero. Su tradicional capacidad de resistencia frente a las dificultades hizo de este pueblo el grupo étnico por excelencia para que se estableciera en unas tierras inhóspitas, de clima extremado y recursos pobres, como eran las de la Meseta norte. Tradicionalmente se ha supuesto que a los pocos años de su llegada a dichas tierras los beréberes, ante las noticias de la rebelión protagonizada por Maysara (beréber como ellos) en el norte de Africa, se sublevaron, dirigiéndose hacia el Moghreb y abandonando, por lo tanto, la áspera cuenca del Duero. Así pues, de acuerdo con esa versión, la presencia beréber en la Meseta norte habría sido como un 
relámpago, por lo que su posible influencia en las tierras que pronto iban a repoblar los cristianos del norte habría sido prácticamente nula.

Este punto de vista, no obstante, ha sido revisado en los últimos años por diversos estudiosos. Así por ejemplo el profesor Ruiz Asencio, estudiando la historia de la actual provincia de Valladolid en el transcurso de los siglos VIII y IX, ha puesto de manifiesto cómo la abundancia de topónimos de origen árabe y beréber que en ella se encuentran, imposible de atribuir a la influencia indirecta de los mozárabes, permite sospechar que hubo musulmanes asentados en las márgenes del Duero hasta finales del siglo IX. Si el topónimo Medina, de indudable raigambre árabe, puede entenderse como testimonio de un acervo común cristiano-musulmán, otros, tal es el caso de Alcazarén, sólo podían brotar, «de labios de gentes arabófonas", dijo Oliver Asín. Asimismo el Mas'ud de San Cebrián de Mazote sería, presumiblemente, un propietario beréber de la zona. Por su parte Villalbarba (villa al-barbar), según la opinión de Ruiz Asencio, fue «un enclave de africanos en medio de una zona poblada por gente autóctona hispano-romana». Todo indica, por lo tanto, que los asentamientos beréberes en torno al río Duero fueron más durederos de lo que se creía.

En cualquier caso el establecimiento de grupos musulmanes en la Meseta norte fue mucho más consistente en la margen izquierda del Duero que en la derecha. El territorio comprendido entre el Duero y el Sistema Central, particularmente en su zona oriental, desde Gormaz hasta Madinaceli, fue un importante bastión militar de Al-Andalus frente a los cristianos del norte, manteniéndose incólume hasta la desintegración del Califato en la primera mitad del siglo XI. El hisn o castillo de Gormaz, objeto de importantes trabajos arqueológicos en los últimos años, fue, en opinión de Levi-Provençal, la «llave de defensa de la línea estratégica califal» en el transcurso de la décima centuria. Construido o restaurado a mediados del siglo $x$, en tiempos del califa al-Hakam 11 , según reza una inscripción, el mencionado castillo de Gormaz revela la maestría lograda, en fechas tan tempranas, por las técnicas constructivas musulmanas.

Más al este la plaza fuerte de Calatañazor pone de manifiesto, asimismo, su vinculación originaria al sistema defensivo de Al-Andalus. Por lo que respecta a Medinaceli, convertida al mediar la décima centuria en el cuartel general de la Marca media del Islam peninsular, fue base de establecimiento de beréberes. Reconstruida la fortaleza por el liberto Galib, Medinaceli desempeñó en la segunda mitad del siglo $x$ un papel 
fundamental como baluarte de contención de las acometidas cristianas. Pero la muerte de Almanzor en aquella plaza auguraba los amargos días del hundimiento el Califato cordobés y con ello el fin de la línea defensiva establecida por Al-Andalus en la región soriana.

Llegados a este punto cabe preguntarse ¿cuáles fueron las aportaciones de los beréberes al mundo cristiano de la Meseta del Duero? Difícil resulta, con los escasos datos de que se dispone, responder a ese interrogante. En el terreno agropecuario se ha puesto mucho énfasis en la actividad de los beréberes como practicantes de la transhumancia, pero ésta ya se conocía en Hispania con anterioridad. En general la agricultura de la cuenca del Duero debe poco a lo arábigo. Es posible, no obstante, que los beréberes fueran agentes de difusión de términos propios del mundo urbano: medina, arrabal, barrio, alfoz, etc. ¿Introdujeron esos términos beréberes cristianizados que se quedaron en la Meseta norte? La pregunta se la hizo T. F. Glick. En todo caso siempre queda la duda entre el aporte beréber y el mozárabe.

\section{LOS MOZÁRABES}

Numerosos elementos de la civilización islámica llegaron a la Meseta norte por un camino insospechado, y en principio paradógico. Nos referimos a los mozárabes, cristianos que vivían en tierras de dominio musulmán pero conservando, gracias a la tolerancia de los adeptos de Mahoma, sus creencias, su lengua y sus costumbres. A partir del siglo $\mathrm{IX}$, no obstante, ante las dificultades que surgieron en Al-Andalus, y acaso también por la atracción que pudo ejercer en ellos la noticia de que en el norte de la Península se había constituido un reino cristiano, grupos diversos de mozárabes emigraron desde Andalucía y otras regiones de Al-Andalus hacia la Meseta norte.

No obstante sigue siendo aún motivo de disputa el papel efectivo desempeñado por los mozárabes en los núcleos cristianos. La opinión tradicional que atribuía a dicho grupo un activísimo papel en la repoblación de las llanuras leonesas, opinión que se encontraba avalada entre otros argumentos por los numerosos topónimos de raigambre arábiga de aquel territorio, fue discutida hace años. Puede verse al respecto el punto de vista formulado por C. Estepa en su libro Estructura social de la ciu- 
dad de León (siglos XI-XIII), en donde dice, a propósito del mozarabismo leonés del siglo $x$, que «probablemente se trataría de una tradición cultural continuadora de lo visigodo».

Sin entrar a discutir esa cuestión vamos a adoptar, en nuestro discurso, una posición más cercana a la tradicional, que valora fuertemente el mozarabismo y ve en él un indudable componente meridional. Pues bien, desde ese supuesto no cabe duda de que los mozárabes aportaron a las ásperas tierras meseteñas numerosos elementos de la tradición religiosa y cultural que habian podido preservar en Al-Andalus, pero a la vez, y en cierta medida de forma incosciente, trasladaron a la cuenca del Duero muchos aspectos propios de la civilización musulmana. Esto último obedecía al hecho de que, poco a poco, habian sido captados por la brillantez de la cultura de la España musulmana, pero también por hábitos de comportamiento y formas de vida específicas de los islamitas de Hispania. No sin razón dijo M. Gómez Moreno de los mozárabes que representaban en la España cristiana «el influjo meridional andaluz».

El denominado arte mozárabe, que floreció en diversas regiones peninsulares, pero particularmente en la cuenta del Duero, y que alcanzó su momento de eclosión en la décima centuria, contiene abundantes elementos de origen islámico, aún visibles hoy en día. Tanto en las técnicas constructivas como en los aspectos ornamentales las iglesias mozárabes de la Meseta norte constituyen un vivo testimonio de la huella del mundo islámico en unos templos edificados para ser dedicados al culto cristiano y, lo que llama más la atención, en una época en la que los enfrentamientos bélicos entre los cristianos y los adeptos de Mahoma estaban a la orden del día. La utilización del arco de herradura califal o de la bóveda de nervios del mismo origen, así como la complicación de las estructuras, aspecto que predispone al misterio típicamente oriental, son, entre otras, algunas de esas muestras de inequívoca génesis arábiga que encontramos en las iglesias mozárabes de la España cristiana. Recordemos, entre otros templos, los de San Miguel de Escalada, en tierras leonesas, o San Baudilio de Berlanga, en la región soriana, con su gran columna central sobre la que apoyan arcos de herradura, semejando el conjunto las ramas de una palmera, árbol ciertamente bien lejano de la fría paramera de Soria. Pero no sólo fue la arquitectura la que siguió un sendero intensamente arabizado. También la miniatura o las artes aplicadas recogieron el espíritu y las formas decorativas del Islam. Las apostillas en árabe que aparecen en la Biblia mozárabe de San Isidoro de León, estudiadas en su día por Casciaro, son un testimonio rotundo de la presencia de la cultura islámica nada más y nada menos que en uno 
de los centros fundamentales de la espiritualidad cristiana de la Península Ibérica de aquella época.

¿Y en el terreno de la economía? ¿Qué aportación cabe atribuir a los mozárabes? Escasa en agricultura, pero notable en la artesanía y el comercio, diríamos de entrada. La escasa influencia ejercida por los mozárabes en el campo agrario se pone de manifiesto al comprobar que el mundo rural de la Meseta norte de los siglos $x$ y $\times 1$ apenas había incorporado las técnicas que por entonces se aplicaban en la agricultura de Al-Andalus. Se ha dicho que los mozárabes no conocían bien la agricultura de irrigación, por lo que difícilmente iban a enseñársela a nadie. Pero todo lo contrario sucede en el ámbito urbano. Desde la misma terminología relacionada con la ciudad hasta las instituciones del mercado, los préstamos arábigos al reino astur-leonés son numerosos. Considerar a los mozárabes agente principal de estos influjos es mucho más que una fundada hipótesis. ¿No está comprobado el papel de los mozárabes en aspectos tales como la fabricación de tejidos o el mismo desarrollo del mercado en la ciudad de León? Sin duda los mozárabes tuvieron mucho que ver en la difusión por tierras cristianas de las innovaciones técnicas propias de la artesanía y del comercio conocidas en Al-Andalus. ¿Cómo explicar si no que en torno al año mil hubiera azogues, en los que se medía en cahices o celemines, bajo la atenta mirada de un zabazoque, en la Meseta del Duero?

En el orden social las diferencias entre Al-Andalus y el reino asturleonés eran profundas. Había, no obstante, formas de relación social que, al menos en apariencia, tenían similitudes. Tal ocurría con las clientelas del territorio musulmán y la dependencia del cristiano. Esto explica que los musulmanes llamaran maulados, (de mawla = cliente) a los hombres de behetría, debido a que con esa palabra ellos percibían la encomendación del campesinado del reino astur-leonés.

En el estado actual de nuestros conocimientos, por lo tanto, cabe atribuir un papel destacado a los mozárabes como transmisores de multitud de elementos culturales desde Al-Andalus hacia las Ilanuras de la cuenca del Duero.

\section{LOS MUDÉJARES}

En la primera mitad del siglo $\mathrm{x}$ se produjo un giro radical en la correlación de fuerzas entre la Cristiandad y el Islam en la Península 
Ibérica. Mientras se hundía el Califato de Córdoba y Al-Andalus se fraccionaba en los denominados "reinos de taifas", los núcleos cristianos iniciaron un proceso de expansión militar que, aunque fue contenido en algunos momentos (presencia de almorávides y almohades), puede calificarse de imparable. Su consecuencia fue la práctica eliminación del poder islámico del solar hispano, con la excepción bien conocida del reino nazarí de Granada.

En líneas generales puede afirmarse que en esta etapa, cuyo comienzo podemos situar a mediados del siglo xI los cristianos mostraron una tendencia más selectiva a la recepción de las novedades culturales procedentes del mundo musulmán. Había cesado, por lo tanto, la receptividad característica de los siglos anteriores. Al mismo tiempo se incrementó la presión para aculturar a los musulmanes y a los judíos que habitaban en los territorios cristianos.

Lo dicho, sin embargo, no supuso, ni mucho menos, la desaparición de la influencia arábiga en el ámbito territorial de Castilla la Vieja y León. Digamos, de entrada, que la presencia islámica en la Meseta norte en el período comprendido entre los siglos $\mathrm{Xl}$ y $\mathrm{XV}$ tiene un nombre nuevo: “mudejarismo». El término aludía, lógicamente, a la denominación de mudéjares, con que se conocía a las gentes de religión musulmana que vivíaii en territorios en los que el dominio político era ejercido por autoridades cristianas.

Los mudéjares de la Meseta norte, ciertamente, son mal conocidos. Por de pronto se abre un interrogante: ¿de dónde procedían? ¿Eran continuadores del poblamiento musulmán instalado en las tierras que caían en poder de las armas cristianas? Esta hipótesis, aplicable a otras regiones peninsulares (el valle del Tajo, Aragón, Valencia) es insostenible para la cuenca del Duero. Todo induce a pensar, y así lo avalan algunos testimonios documentales, que a partir del siglo XII, y particularmente en el XIII, se produjo una emigración de mudéjares desde tierras meridionales hacia la Meseta norte, siendo el antiguo reino de Toledo el lugar de origen preferente de los musulmanes citados. Sin duda no hubo grandes movimientos de población, pues en todo momento los mudéjares residentes en la cuenca del Duero en los siglos bajomedievales fueron escasos. Más bien lo que hubo fue un goteo continuo de familias que, por una $u$ otra razón, salían del valle del Tajo o de otras comarcas meridionales de Hispania para establecerse en la Meseta norte, en donde esperaban rehacer su vida. 
Hay muchos problemas sin resolver en relación con los mudéjares de Castilla la Vieja y León, lo que obedece principalmente a la carencia de fuentes documentales. Pero por de pronto el simple hecho de la llegada de familias musulmanas a esas tierras rompe las hipótesis, un tanto simplistas, que hacian de la Meseta norte el reducto de un cristianismo beligerante contra el Islam. Tengamos en cuenta que, a diferencia de lo sucedido con los mozárabes, los mudéjares constituían una comunidad islámica, en tanto que aquellos eran simplemente cristianos más o menos influidos por la cultura arábiga. Pero las circunstancias habían cambiado notablemente, de ahí que los mudéjares se encontrasen en una clara posición de sometimiento. F. Maillo ha reflejado certeramente la situación de esos grupos al señalar cómo "unas comunidades mudéjares, antes pertenecientes a un pueblo independiente, se han convertido en grupo dominado en el interior de la nueva sociedad que forma con sus dominadores, con la experiencia efectiva de saberse súbditos de segunda de los reyes cristianos, y con posiciones sociales y políticas de inferioridad". No es extraño que en este contexto la aculturación o incluso la apostasía estuviesen a la orden del día entre los mudéjares.

La debilidad en que se encontraban los mudéjares en la Castilla bajomedieval (tanto en el conjunto de la corona como específicamente en la Meseta norte) era manifiesta. Por de pronto fueron escasos en número, si bien sus efectivos parece que fueron reduciéndose en los últimos siglos de la Edad Media, debido a la emigración de algunos hacia la Granada nazarí y a la conversión al cristianismo de otros. Las investigaciones de $M$. A. Ladero han permitido conocer el número aproximado de familias mudéjares que vivían en la cuenca del Duero en los últimos años del siglo XV. Se localizan morerías en unas 20 villas y ciudades, si bien en su mayoría eran muy reducidas. La mayor era la de Ávila, que contaba con unas 200 familias, siguiéndole, con unas 100-125 familias, las morerías de Valladolid, Arévalo y Agreda.

Los mudéjares, por otra parte, eran un grupo débil desde el punto de vista económico. Había algunos individuos poseedores de fortunas importantes (comerciantes, propietarios de tierras o casas, etc.), pero en muy escaso número. La mayoría de los mudéjares se dedicaban a realizar trabajos modestos, tanto en el ámbito urbano (carpinteros, albañiles, pequeños comerciantes...) como en el rural (hortelanos preferentemente).

Pero el aspecto más significativo de los mudéjares no consistía en la debilidad de sus efectivos demográficos ni de su posición económica, sino en el hecho de que constituyeran un grupo marginal. Por otra parte 
al tiempo que crecía la hostilidad de las masas populares cristianas hacia los judíos se acentuaba el aislamiento de las minorías mudéjares. Las duras disposiciones tomadas a comienzos del siglo $\mathrm{XV}$, en tiempos de la minoridad de Juan II de Castilla, contra hebreos y mudéjares, dio lugar a un endurecimiento de las condiciones de vida de esas minorías. En adelante los mudéjares fueron recluidos en barrios especiales, auténticos guettos. Más aún, la progresiva identificación del poder político imperante con un determinado credo religioso, en este caso el cristianismo, desembocó en la expulsión de los mudéjares de Castilla el año 1502. Se admitía su conversión al cristianismo, pero en modo alguno se aceptaba la práctica pública de su fe islamita. Con esas conversiones aparecía en el horizonte un grupo nuevo, los moriscos.

Ahora bien, no siempre fueron los mudéjares un grupo testimonial. Las investigaciones de A. Rucquoi acerca del Valladolid medieval han puesto de manifiesto que la comunidad mudéjar de aquella villa estaba relativamente integrada en la vida urbana. Ciertamente las medidas antisemitas del año 1412 derivaron en el abandono de su antiguo hábitat, para trasladarse a unos terrenos del cabildo de la colegiata situados al sur del núcleo (el futuro barrio de Santa María). Es asimismo cierto que predominaban entre los mudéjares las profesiones de carácter artesanal, como carpinteros, alfareros, hortelanos, trabajadores de la construcción, etcétera. Pero en sentido contrario cabe señalar el mantenimiento de alcalde propio, la existencia en el seno de la comunidad de rentistas y grandes mercaderes, la consecución por algunos de sus miembros de importantes privilegios reales $\mathrm{y}$, ante todo, la destacada participación del grupo en defensa del monarca Enrique IV frente a las banderías nobiliarias en el año 1465. Un grupo marginal difícilmente podía haber ejercido ningún protagonismo en esos acontecimientos políticos. A. Rucquoi concluye: esa integración de los mudéjares en la vida de Valladolid explica que "en su mayoría, hayan escogido la conversión antes que el exilio en 1502».

Mas tampoco queremos poner demasiado énfasis en el ejemplo de los mudéjares vallisoletanos. Como idea general seguimos pensando en la debilidad de ese grupo en la Castilla bajomedieval. En cualquier caso nadie pone en duda la fuerza alcanzada en esos mismo siglos por el "mudejarismo", expresión que sintetiza una serie de elementos de indiscutible tradición musulmana que se plasmaron en campos muy variados, tales como las artes plásticas o determinadas formas de la vida diaria. 
En el terreno artístico se ha dado la denominación de mudéjar a un arte ecléctico que, tomando como base, según la época de que se trate, el estilo románico o el gótico, insufló en aquellas estructuras numerosísimos elementos de origen muslim. El uso del ladrillo en los muros, de la madera en las techumbres (recordemos los ricos y deslumbrantes artesanados) y del yeso para ornamentar, son aspectos bien conocidos del mudejarismo artístico. La iglesia de La Lugareja en Arévalo o la torre de San Nicolás de Coca, que evoca el alminar de la mezquita cordobesa, son ejemplos bien significativos del románico-mudéjar. Pero sin duda fue mucho más espectacular el despliegue alcanzado en tierras de la Meseta norte por el estilo gótico-mudéjar. En el monasterio femenino de las Huelgas de Burgos, centro de especial protección por parte de los reyes de Castilla, la impronta islámica irrumpe con fuerza en la capilla de la Asunción, con su bóveda de crucería califal, o en las yeserías del claustro de San Fernando, que anticipan la decoración posterior de la Alhambra granadina. En el siglo XIV, por su parte, se erigió el imponente palacio real de Alfonso XI en Tordesillas. Lo muslim aparece allí por doquier: la red de rombos, típicamente almohade, en la fachada; los arcos lobulados en el patio, así como la decoración de lazos del mismo recinto; el fastuoso artesonado, etc. Pero asimismo son muchos los castillos (Coca, Medina del Campo o Arévalo, por mencionar algunos de los más señeros), las murallas, las puertas, etc., que proclaman a lo largo y a lo ancho de la cuenca del Duero cómo las formas artísticas islámicas habían logrado cautivar a los cristianos.

El mudejarismo era, por otra parte, una serie de hábitos en el vestir, en el comer, en expresiones corrientes de la vida diaria del pueblo, en el uso de instrumentos del campo o del hogar. Frente al deslumbramiento ejercido entre los sectores nobiliarios de la Castilla bajomedieval por las modas francesas y flamencas, la masa popular, aunque proclamara en voz alta su orgullo de cristianos y su inveterada hostilidad a los infieles, estaba de hecho impregnada, hasta niveles que hoy nos resulta muy difícil captar, por la civilización islámica. ¿Y qué decir del posible transfondo oriental (léase mudejarismo) de determinadas obras literarias? Un ejemplo típico en este sentido puede ser el Libro del Buen Amor, en el que algunos autores han visto un fuerte peso de lo mudéjar, aunque la más reciente crítica explica sus caracteres básicamente en función de la tradición europea. 


\section{CONCLUSIONES}

La última etapa de la presencia musulmana en tierras de la cuenca del Duero está ligada a los moriscos. Su entrada en las filas del cristianismo, con frecuencia efectuada sin convicción, no puso fin, ni mucho menos, a sus tradiciones culturales y a sus formas de vida, fuertemente impregnadas de orientalismo. Por lo demás a los mudéjares de la Meseta norte que, una vez aceptado el bautismo, permanecieron in situ, hay que añadir la llegada a esas tierras de algunos grupos de moriscos, desterrados de Granada después de la guerra de las Alpujarras. En Ávila, Valladolid y otras ciudades castellanas se asentaron esos moriscos, postrer testimonio vital del Islam peninsular. Pero su vida se desarrolló con muchas dificultades, por lo que su condición de marginalidad no hizo sino acentuarse. Por otra parte en los primeros años del siglo XVII se ordenó la expulsión de los moriscos de los diversos reinos peninsulares, lo que significa que apenas vivieron un siglo en el solar hispano.

Una vez efectuado este rápido repaso ¿se impone alguna conclusión? Ciertamente Cristiandad e Islam pugnaron durante siglos en la «piel de toro", pero al mismo tiempo intercambiaron sus culturas y sus formas de eniender el mundo. La consecuencia de ello, en opinión de Américo Castro, fue la creación de una peculiar vividura hispánica, en la que confluían, aparte de lo hebraico, lo cristiano y lo muslim. No vamos a discutir ese punto de vista, suficientemente debatido desde hace décadas desde las más variadas posiciones. Pero de lo que no cabe duda, restringiendo nuestro campo de observación a la Meseta norte, un territorio escasamente "colonizado" por los musulmanes, es de que la huella de lo islámico surge por muchos sitios, apenas se excarva un poco. Son huellas que remontan a la Edad Media y que de una u otra forma, a través de restos materiales o de elementos de la vida cultural y de las mentalidades, se han preservado hasta nuestro días. ¿No se ha dicho, por Iñíguez Almech, que incluso muchos capiteles de algunas de las más conocidas iglesias románicas de la cuenca del Duero (San Isidoro de León, San Martín de Frómista, etc.), tradicionalmente interpretados de acuerdo con esquemas simbólicos, pueden ser una traducción plástica de los hadices o tradiciones musulmanas?

Así pues, Castilla la Vieja y León, solar en el que se configuró un núcleo político cristiano que durante siglos encabezó la cruzada contra los infieles, deben al Islam mucho más de lo que en principio pudiera 
sospecharse. Olvidadas las viejas querellas del pasado, y poniendo el acento más en lo que une que en lo que separa, es necesario intensificar el diálogo de dos culturas tan ancestrales y que tienen tantos elementos de aproximación. 
